\section{Posterior Reversible Encephalopathy Syndrome}

\section{To the Editor:}

We read with interest the article by Varaprasad, et al ${ }^{1}$ in which the authors studied 13 patients with systemic lupus erythematosus (SLE) and posterior reversible encephalopathy syndrome (PRES) presenting clinical and magnetic resonance imaging (MRI) features. All patients were female, ranging in age from 14 to 37 years. The duration of SLE ranged from 1.5 to 36 months. Eleven patients had seizures, 10 had headaches, 7 had loss of consciousness and vomiting, 3 had transient vision loss, and each presented paraparesis and left hemiplegia. All patients showed both early stages of SLE and hypertension. Eight patients were receiving corticosteroids and 4 were taking monthly cyclophosphamide.

In 2007, we described the first case of PRES associated with SLE and thrombotic thrombocytopenic purpura ${ }^{2}$. In that case, the neurologic symptoms, the characteristic MR images, and the prompt full response to treatment enabled the diagnosis (Figure 1).

After that, we followed 2 other patients with PRES. Of the 3 total cases, 1 had SLE, another presented with SLE and thrombotic thrombocytopenic purpura, and the third with postinfection glomerulonephritis. Two were women and all ages ranged from 15 to 31 years. The duration of SLE was 1 month and 108 months, respectively, and SLE was active in both patients (SLE Disease Activity Index of 28 and 12). Similar to Varaprasad's series, all our patients presented with headaches, hypertension, renal involvement, and seizures; 1 patient had loss of consciousness and hemiplegia.

Although some authors do not specify the duration of SLE in their reports, others describe the diagnosis of PRES in patients with SLE between 1 and 20 years' duration $3,4,5$.

Most patients showed active lupus, with nephritis being the most common accompaniment. Renal failure and severe hypertension are known risk factors for the development of PRES ${ }^{6}$. The occurrence of PRES in normotensives and treatment-naive patients may explain that the endothelial dysfunction due to disease activity plays an important pathogenetic role ${ }^{7}$.

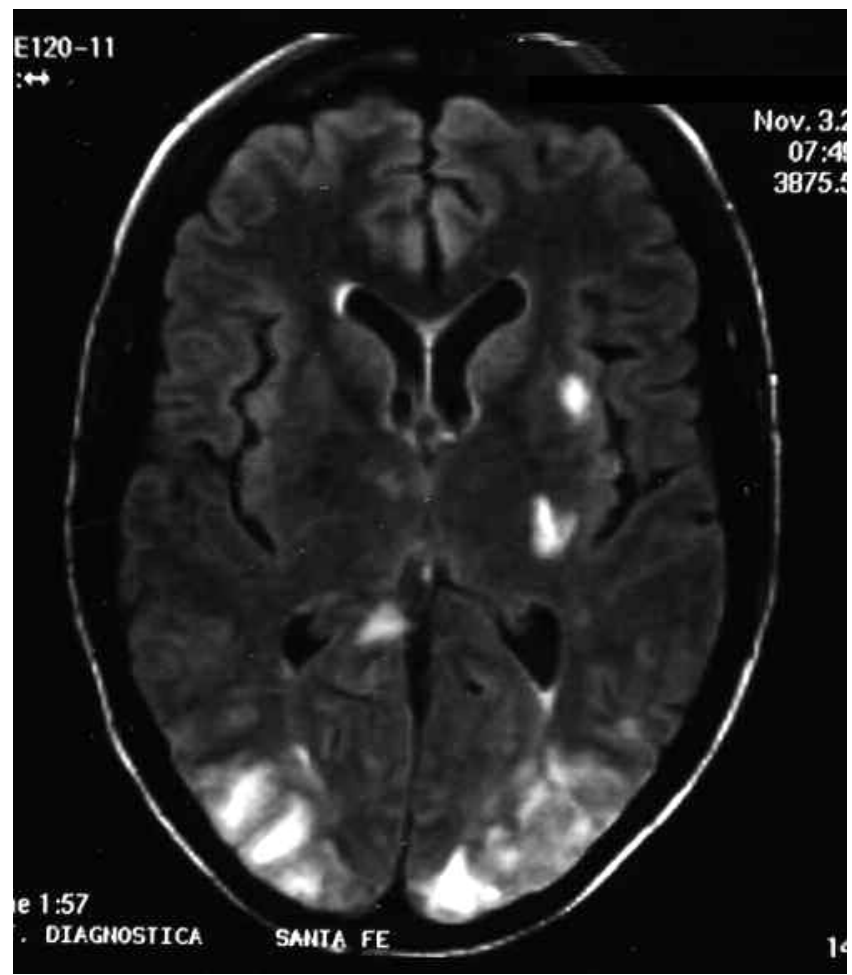

Figure 1. Magnetic resonance image shows occipital bilateral hyperintense images on $\mathrm{T} 2$ and fluid-attenuated inversion recovery sparing the calcarine and paramedian occipital lobe structures.
On the MR images, lesions may be observed in detail. They are hypointense on $\mathrm{T} 1$ and hyperintense on $\mathrm{T} 2$ images, with greater sensitivity of the fluid-attenuated inversion recovery and of the apparent diffusion coefficient map. They are typically bilateral and symmetrical and they follow the calcarine and paramedian occipital lobe structures. This allows a differentiation from those observed in the obstructions of the posterior cerebral artery or in the top of the basilar artery, where the calcarine region is invariably compromised. Less frequently, they may be found in the cerebral cortex, cerebellum, basal ganglia, and frontal lobe $e^{6,8}$. These latter atypical characteristics and the report of some cases with permanent sequels allowed Alurralde, et al to question the use of the prefix "leuco" and the terms "posterior" and "reversible" in the PRES nomenclature".

Our patients' MRI presented PRES with diffuse bilateral gray and white matter involvement, especially in the posterior fossa. One patient's MRI also showed lesions in the cerebral cortex, cerebellum, basal ganglia, and frontal lobe. These lesions normalized after the treatment.

The 3 patients were treated with antihypertensive drugs. Two also received methylprednisolone intravenously (IV), 1 received meprednisone $40 \mathrm{mg} /$ day orally, 2 were treated with antiepileptic drugs, and 2 with cyclophosphamide IV. Plasmapheresis was used with 1 patient. Similar to Varaprasad's series, the time for recovery from PRES was 10 days in 2 patients and 1 day in the third patient.

Urgent and aggressive treatment of arterial hypertension, seizures, and renal failure, in addition to dose decreases or suspension of treatment with immunosuppressive agents, is the key to reversibility of PRES ${ }^{2}$.

PRES is a serious clinical multifactor radiologic manifestation and should be included in the differential diagnosis of all patients with connective tissue disease who have seizures, severe arterial hypertension, and renal failure, or who are treated with immunosuppressive drugs.

MRI is the chosen technique for a fast differential diagnosis, as it allows prompt treatment and therefore helps decrease the risk of permanent sequelae.

\section{ACKNOWLEDGMENT}

The authors are grateful to Raúl A. Galoppe, PhD (Montclair State University, Montclair, NJ, USA) for his help in translating this report.

ALBERTO ORTIZ, MD; SUSANA ROVERANO, MD; SERGIO PAIRA, MD, Rheumatology Section, Hospital J.M. Cullen, Santa Fe, Argentina. Address correspondence to Dr. A. Ortiz, Rheumatology Section, Department of Internal Medicine, Hospital J.M. Cullen, Crespo 2752-(3000), Santa Fe, Argentina. E-mail: albertoortiz_4@hotmail.com

\section{REFERENCES}

1. Varaprasad IR, Agrawal S, Prabu VNN, Rajasekhar L, Kanikannan MA, Narsimulu G. Posterior reversible encephalopathy syndrome in systemic lupus erythematosus. J Rheumatol 2011;38:1607-11.

2. Cassano G, Zunino A, Gongora V, Roverano S, Paira S. Reversible posterior leukoencephalopathy in systemic lupus erythematosus with thrombotic thrombocytopenic purpura. J Clin Rheum 2007; $13: 55-7$

3. Shin KC, Choi HJ, Bae YD, Lee JC, Lee EB, Song YW. Reversible posterior leukoencephalopathy syndrome in systemic lupus erythematosus with thrombocytopenia treated with cyclosporine. J Clin Rheumatol 2005;11:164-6.

4. Thaipisuttikul I, Phanthumchinda K. Recurrent reversible posterior leukoencephalopathy in a patient with systemic lupus erythematosus. J Neurol 2005;252:230-1.

5. Primavera A, Audenino D, Mavilio N, Cocito L. Reversible posterior leucoencephalopathy syndrome in systemic lupus and vasculitis. Ann Rheum Dis 2001;60:534-7.

6. Hinchey J, Chaves C, Appignani B, Breen J, Pao L, Wang A, et al. A reversible posterior leukoencephalopathy syndrome. N Engl J Med 1996;334:494-500.

7. Johnson SR, Harvey PJ, Floras JS, Iwanochko M, Ivanez D, 
Gladman DD, et al. Impaired brachial artery endothelium dependent flow mediated dilation in systemic lupus erythematosus: preliminary observations. Lupus 2004;13:590-3.

8. Garg RK. Posterior leukoencephalopathy syndrome. Postgrad Med J 2001;77:24-8.
9. Alurralde AM, di Egidio M, Saizar R, Consalvo D, Villa AM. Reversible posterior leucoencephalopathy syndrome: A case report and review of its physiopathology based on neuroradiological findings [Spanish]. Rev Neurol 2004;38:541-4.

J Rheumatol 2012;39;4; doi:10.3899/jrheum.111192 